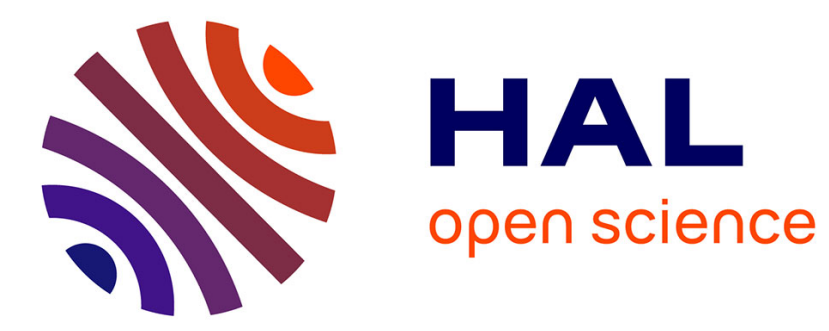

\title{
The D-BEST based Digital Innovation Hub Customer Journeys Analysis Method: A Pilot Case
}

Claudio Sassanelli, Sergio Gusmeroli, Sergio Terzi

\section{To cite this version:}

Claudio Sassanelli, Sergio Gusmeroli, Sergio Terzi. The D-BEST based Digital Innovation Hub Customer Journeys Analysis Method: A Pilot Case. 22nd Working Conference on Virtual Enterprises (PRO-VE 2021), Nov 2021, Saint-Etienne, France. pp.460-470, 10.1007/978-3-030-85969-5_43 . emse-03346116

\section{HAL Id: emse-03346116 https://hal-emse.ccsd.cnrs.fr/emse-03346116}

Submitted on 26 Nov 2021

HAL is a multi-disciplinary open access archive for the deposit and dissemination of scientific research documents, whether they are published or not. The documents may come from teaching and research institutions in France or abroad, or from public or private research centers.
L'archive ouverte pluridisciplinaire HAL, est destinée au dépôt et à la diffusion de documents scientifiques de niveau recherche, publiés ou non, émanant des établissements d'enseignement et de recherche français ou étrangers, des laboratoires publics ou privés. 


\title{
The D-BEST based Digital Innovation Hub Customer Journeys Analysis Method: A Pilot Case
}

\author{
Claudio Sassanelli, Sergio Gusmeroli, Sergio Terzi \\ Department of Management, Economics and Industrial Engineering, Politecnico di Milano, \\ Piazza Leonardo da Vinci, 3220133 - Milan - Italy \\ \{claudio.sassanelli@polimi.it; sergio.gusmeroli@polimi.it; sergio.terzi@polimi.it\}
}

\begin{abstract}
Digital Innovation Hubs (DIHs) are ecosystems sustaining European enterprises to overcome innovation hurdles and push Europe as a world leading innovator in the Fourth Industrial Revolution context. They operate as a onestop-shop, characterized by four main functionalities, i.e., test before invest, support to find investments, innovation ecosystem and networking, skills and training. These functionalities are addressed through the delivery of a set of services, grouped in the five macro-classes of services of the Data-driven Business-Ecosystem-Skills-Technology (D-BEST) model, a reference model able to configure the service portfolios of DIHs and to model collaborative networks in the I4.0 era. The model has been used in the DIH4CPS project to classify the extant service portfolios of the DIHs belonging to the network, to detect which new services should be provided in the future by the network of DIHs, and to identify opportunities for collaboration among DIHs fostering the creation of a pan-European DIH. However, to support an easier codification of such dynamics directly involving companies in the innovative DIHs ecosystems, a Customer Journey (CJ) analysis method has still to be built. This paper presents the D-BEST-based CJ analysis method, identifying typical digital transformation processes for the two main categories of customers of a DIH, Technology Users and Technology Providers.
\end{abstract}

Keywords: Digital Innovation Hub, customer journey, service portfolio, digital transformation.

\section{Introduction}

Digital Innovation Hubs (DIHs) are ecosystems sustaining European enterprises to overcome innovation hurdles and push Europe as a world leading innovator in the Fourth Industrial Revolution context. They operate as a one-stop-shop, characterized by four main functionalities, i.e. test before invest, support to find investments, innovation ecosystem and networking, skills and training (European Commission, 2018). Their main scope is to enable companies of different types, sectors, and dimensions to exploit digital innovations for strengthening their solutions portfolios, streamlining their processes and adjust their business models to the digital dimension. Among the several projects funded by the European Commission (EC), the DIH4CPS project (DIH4CPS - Digital Innovation Hub for Cyber-Physical Systems, 2020) is 
working to create an embracing, interdisciplinary network of DIHs and solution providers, focussed on cyber-physical and embedded systems (CPES), interweaving knowledge and technologies from different domains, and connecting regional clusters with the pan-European expert pool of DIHs. DIH4CPS innately builds on an extensive existing network, adds value to its existing knowledge transfer capabilities and guarantees the sustainability of the growing DIH network. The project aims at expanding the already existing network and creating an integrated platform for DIHs from different, especially digitally underdeveloped, sectors and regions. The operating context of the DIH4CPS ecosystem is the CPES domain, with the scope of identifying and materialising service-based collaboration processes among a network of DIHs oriented to improving this kind of technologies. So far, the project has developed the Data-driven Business-Ecosystem-Skills-Technology (D-BEST) model, a reference model able to configure the service portfolios of DIHs, modelling collaborative networks in the I4.0 era. The model is the result of an iterative development: conceived originally as the ETB model (Butter et al., 2019), it evolved in the ETBSD model (used in the MIDIH Project (2020)). Finally, it evolved in the DBEST, used in the DIH4CPS project (2020) (Sassanelli et al., 2020) to classify the extant service portfolios of the DIHs belonging to the network, to detect which new services should be provided in the future by the network of DIHs, to identify opportunities for collaboration among DIHs and their stakeholders to be combined in a pan-European DIH. However, to support an easier codification of such dynamics directly involving companies in the innovative DIHs ecosystems, a Customer Journey (CJ) analysis method has still to be built. The D-BEST-based DIH CJ analysis method (whose need and development has been grounded on the practical experience of several European Commission-funded Innovation Action projects belonging to the I4MS initiative) identifies typical digital transformation processes for the two main categories of DIH customers: Technology Users (TU) and Technology Providers (TP). TUs are those companies using technologies to best perform their business, typically manufacturing companies. Instead, TPs are instead those companies whose business is to develop new technologies, typically digital technologies developers. Starting from the service portfolios of the DIHs mapped through the use of the DBEST model, this paper aims at outlining how CJs can be analysed and configured in a DIH for both TU and TP, presenting the results of the pilot case of the Politecnico di Milano's (POLIMI) DIH. In this analysis, the D-BEST services composing the DIHs service portfolios are combined towards the implementation of DIHs Unique Value Proposition, building and defining flexible service workflows for DIH customers. The paper is structured as follows. Section 2 presents the research method used to develop the CJ method and introduces the case. Section 3 presents the CJ method and Section 4 discusses its role to foster the creation of interdisciplinary networks of DIHs supporting the digital transformation process, presenting limitations and further research. 


\section{Research Method}

This section is aimed at describing how the CJs have been built in the DIH4CPS ecosystem, a H2020 project funded by the European Commission. The input of this work has been the result coming from a survey previously conducted in the project, based on the D-BEST model and aimed at obtaining a preliminary configuration of the service portfolios of the DIHs belonging to the project's ecosystem. This paper presents the specific results of the pilot case so far conducted in the project, the DIH of the POLIMI, presenting part of the activities conducted by the Manufacturing Group of the Business School. The main goal is to use the experiment conducted in this pilot case to develop the method to systematically build the CJS of the customers (TU and TP) of a DIH. This methodology will be then extended to the other 10 DIHs belonging to the DIH4CPS ecosystem. Therefore, starting from the result of the survey, the first task conducted has been the organization of a workshop with the representatives of the DIH analysed (Project Manager, Research Coordinator, Business Developer) to obtain the complete overview of the service portfolio. Then, a second workshop with the same users has been organized, with the support of an online collaborative platform, to build the CJs of the TP and TU of the DIH.

\section{Results}

The DIH4CPS project, with the main aim of easing the shift towards digitization of the manufacturing SMEs through the help of DIHs as innovation ecosystems, has to focus on the codification of typical CJs. Indeed, the progressive adoption of new technologies and digital applications strictly depends on the company maturity to employ them in its manufacturing systems. In fact, the digital transformation journey is a constant path, affected by several business areas as the business strategy, the operating model and business model, leading the company to master the Industry 4.0. Digital transformation entails the support of an innovation ecosystem. The role of a DIH is to support companies (especially SMEs) to achieve a superior digitization level compared to the current one by offering services according to the Digital Transformation pillars. Despite this is a technology-related path, the definition of blueprints, where DIHs' tools and services are allocated to cover a wide range of requirements to foster the digital transformation of manufacturers, are needed. In the following sub-sections, two step-based digital transformation journeys created in the DIH4CPS project are presented: they are the TU CJ (for manufacturing companies) and the TP CJ (for digital developers and providers).

\subsection{Technology End-User Customer Journey Templates}

The TU CJ is composed of five steps (Observation, Awareness, Experimentation, Experience, and Adoption), chaperoning the manufacturers towards a higher level of digital maturity. During Observation manufacturers access to content in a passive 
way, driven by wonder or by individuals looking for information on the digitization concept, through popular information channels. Then, the Awareness phase follows, once the contact company-DIH has materialized, accessing to this network. In this phase, the company actively looks for targeted information with an open up behaviour to new chances. In this moment, the company needs to know its digital maturity level and plan for a roadmap to be pursued in the following experimentation phase. The $\mathrm{DIH}$ provides here technological or informative services as events, webinars, demo rooms, experience centres, courses and basic training on the I4.0. During the Experimentation, the DIH and its own network sews the customized digital dress to the company: new technological solutions and competences are proposed to meet the opportunities and the expected benefits of digital change. Services here support the new digital solutions concepts development, delivering proofs of concepts (PoC) and testing them in provided facilities (max TRL 4-5). In the Experience phase, the technologies are shifted in the company's facility at the structured level, limited at a test/pilot scale. Service provided are here typically training of personnel (upskilling /re-skilling), support for organizational change (operational, decision-making and information management processes), technological development of customized solutions according to the real environment of the enterprise and definition of structured KPIs of the digital transformation. Finally, in the Adoption phase occurs the decision of developing the new solution at the whole company level, flanked by investments in the innovation of the entire company. Services supporting the definition of new business models, together with strategic consulting, support for massive deployment and new project management methods.

\subsection{TP Customer Journey Template}

For TPs, the CJ is a skill-demanding process model going through five main phases leading to the final product market launch (Ideation, Design \& Engineering, MVP, Verification \& Validation, Go to Market).

During Ideation the business idea is conceived (flanked by preliminary architecture of the solution to be implemented and by the key technical milestones and (functional and non-functional) requirements to be addressed in the following stages), through a creative process (through methods as Brainstorming, Creative thinking, Creative matrix, Wall of idea, etc). Services offered to TP are workshops/webinars on design thinking, SWOT analysis, idea market positioning, hackathons. Once consolidated the business idea, the Design and Engineering phase starts with the design phase and the specifications for its technical development. Tools that could be useful in this phase are: Technical pills, Dockers, Kubernetes, visual analytics, UX, UI, an assessment about how to validate the solution or customer discovery (validation of the idea to see if the idea has a market). In this phase there could be some deviations from the original business idea since current software components cannot meet the requirements or new functionalities can be added without cost increases. A comprehensive Market Requirements Document (MRD) needs to be prepared in this phase (to articulate the new product plan including customers, buyers, goals, usecases, requirements, and specification sizing), leading to a more streamlined Minimum Viable Product (MVP) definition, useful for the company to validate products value and growth hypotheses as fast as possible. MVP needs to be 
experimented to be confirmed or refuted. Tools such as FIWARE Lab, credit from Google/Amazon cloud, 3D Printers, sensors, etc., can be provided in this stage as well as any service to find economical support for subcontracting to realize the final MVP and elaborating the business part programme. Verification and validation are essential parts of the product development process (Ulrich and Eppinger, 2012). On one hand, verification (e.g., automated tests, integration tests and code review) checks if the solution confirms the specification and looks for mistakes made in the model. On the other hand, validation assures the satisfaction of user needs and conformity with the solution intended use, involving the revision of the market requirements (e.g., on-site surveys/questionnaires, user interaction monitoring and tracking) and the funds finding. The last phase, Go to market, deals with the commercialization of the product to be launched. Typical activities are the definition of a commercialization strategy (depending on the milestones to be reached and covering issues in the legal domain as IPR protection and management, management of legal aspects), of a communication and marketing plan, with the identification of channels for distribution and the definition of the revenue model.

\subsection{The Pilot Case: The POLIMI DIH}

The D-BEST model was used, through the launch of a survey, to configure the service portfolios of all the DIHs of the DIH4CPS network. In this section, the services composing the Politecnico di Milano DIH portfolio have been allocated on the two five-step CJs to build its unique value proposition for TU (Figure 1) and TP (Figure 2 ). The service portfolio has been fully detailed, going through the five macro-areas of the D-BEST model (Table 1):

Table 1. The Polimi DIH service portfolio based on the D-BEST reference model

\begin{tabular}{|c|c|c|}
\hline Class of service & Service Instance & POLIMI's service instance \\
\hline \multicolumn{3}{|c|}{ ECOSYSTEM } \\
\hline SME and People & Academic conferences and workshops; & WMF; Open days; Conferences; \\
\hline $\begin{array}{l}\text { Engagement and } \\
\text { brokerage }\end{array}$ & Training sessions and Other Events & $\begin{array}{l}\text { Webinar \& Seminar (Observatory } \\
\text { Transition I4.0) }\end{array}$ \\
\hline \multirow[t]{2}{*}{$\begin{array}{l}\text { Technology } \\
\text { scouting }\end{array}$} & Identification of emerging technologies & $\begin{array}{l}\text { Research projects results; Reports, } \\
\text { articles. }\end{array}$ \\
\hline & $\begin{array}{l}\text { Communication of technology related } \\
\text { information to organizations }\end{array}$ & $\begin{array}{l}\text { Research projects results; Reports, } \\
\text { articles. }\end{array}$ \\
\hline \multirow[t]{4}{*}{$\begin{array}{l}\text { Communication and } \\
\text { Trend watching }\end{array}$} & Sharing of best practices experiences & $\begin{array}{l}\text { Research projects results; Reports, } \\
\text { articles; Webinar \& Seminar } \\
\text { (Observatory Transition I4.0) }\end{array}$ \\
\hline & $\begin{array}{l}\text { Invitation of experts in business and } \\
\text { entrepreneurship, or industry sectors to } \\
\text { give talks and interact with (potential) } \\
\text { customers and partners }\end{array}$ & \\
\hline & $\begin{array}{l}\text { DIH business model definition and } \\
\text { updating through up-to-date information } \\
\text { on the trends in the market }\end{array}$ & \\
\hline & Provision of trend reports & $\begin{array}{l}\text { Benchmark from CLIMB/DREAMY } \\
\text { maturity models results }\end{array}$ \\
\hline $\begin{array}{l}\text { Ecosystem } \\
\text { management }\end{array}$ & $\begin{array}{l}\text { Definition of Intellectual Property (IP) } \\
\text { rules }\end{array}$ & \\
\hline \multicolumn{3}{|c|}{ TECHNOLOGY } \\
\hline $\begin{array}{l}\text { Technology concept } \\
\text { development/ Proof }\end{array}$ & Proof of concept development & Industry 4.0 Lab \\
\hline
\end{tabular}




\begin{tabular}{|c|c|c|}
\hline of Concept (PoC) & & \\
\hline $\begin{array}{l}\text { Access to } \\
\text { infrastructure and } \\
\text { technological } \\
\text { platforms }\end{array}$ & Provision of access to lab facilities & Industry 4.0 Lab \\
\hline \multicolumn{3}{|c|}{ BUSINESS } \\
\hline $\begin{array}{l}\text { Methods and Tools, } \\
\text { Business } \\
\text { Operations } \\
\text { Modelling }\end{array}$ & $\begin{array}{l}\text { Provision of training and development in } \\
\text { business skills and entrepreneurship (e.g., } \\
\text { formal courses, workshops, seminars) }\end{array}$ & $\begin{array}{l}\text { Courses on Value proposition } \\
\text { Canvas \& Business Model Canvas }\end{array}$ \\
\hline Secondment & $\begin{array}{l}\text { Orienting partners to the needed training } \\
\text { organization }\end{array}$ & \\
\hline $\begin{array}{l}\text { Development of } \\
\text { proposals }\end{array}$ & $\begin{array}{l}\text { Provision of technical assistance in the } \\
\text { proposal development process to comply } \\
\text { with specific proposal requirements (e.g., } \\
\text { for project funding) }\end{array}$ & Building of consortia; Open calls \\
\hline \multicolumn{3}{|c|}{ SKILLS } \\
\hline $\begin{array}{l}\text { Maturity } \\
\text { Assessment }\end{array}$ & $\begin{array}{l}\text { Assessment of the maturity companies, } \\
\text { e.g.: assessment of company readiness for } \\
\text { Industry } 4.0\end{array}$ & $\begin{array}{l}\text { DREAMY digital maturity } \\
\text { assessment model }\end{array}$ \\
\hline $\begin{array}{l}\text { Human skills } \\
\text { maturity assessment }\end{array}$ & $\begin{array}{l}\text { Assessment of human skills maturity } \\
\text { (e.g., regarding skills in Industry 4.0) }\end{array}$ & $\begin{array}{l}\text { CLIMB/DREAMY maturity } \\
\text { assessment models }\end{array}$ \\
\hline Skills Improvement & $\begin{array}{l}\text { Definition of educational programs } \\
\text { (forming Industry } 4.0 \text { employees and } \\
\text { workers) }\end{array}$ & $\begin{array}{l}\text { Workshops (e.g., Industry } 4.0 \\
\text { Overview, Predictive Maintenance, } \\
\text { MOVE TO 4.0). } \\
\text { Master's Program in Industrial } \\
\text { Engineering and the MBA and } \\
\text { Masters' programs about Industry } 4.0\end{array}$ \\
\hline \multicolumn{3}{|c|}{ DATA } \\
\hline Data analytics & $\begin{array}{l}\text { Provision of data analytics services: } \\
\text { semantic analysis, Data discovery, } \\
\text { Advanced Data Analytics (Edge } \\
\text { Analytics, Cloud Analytics) services }\end{array}$ & \\
\hline $\begin{array}{l}\text { Decision support } \\
\text { and development }\end{array}$ & $\begin{array}{l}\text { Provision and development of decision } \\
\text { support services: cognition, prediction } \\
\text { and prescription, simulation, machine } \\
\text { learning, reinforcement, DNNs, formal } \\
\text { logics }\end{array}$ & \\
\hline User experience & $\begin{array}{l}\text { Provision of support/consultancy services } \\
\text { for user experience, navigation and } \\
\text { exploration }\end{array}$ & Dashboarding and KPIs \\
\hline
\end{tabular}

\subsubsection{Technology End-User Customer Journey}

Observation: The generic customer journey of a TU starts with the observation step. During this first phase, POLIMI organizes (and participates to) many public events like conferences, webinars, open days and workshops (e.g., of the Observatory Transition I4.0) that TUs can access to understand and realize which are the possible application of digital technologies in the manufacturing context. Such events can be focused on specific topics, to provide the extant state of theory and practice to both academics (professors, researchers, students, etc.) and practitioners (manufacturing companies and professionals). A reference example of these events is the World Manufacturing Forum (WMF), a yearly event of general interests in the manufacturing digital domain organized by the World Manufacturing Foundation together with POLIMI. The WMF indeed aims to enhance and spread industrial culture worldwide, as a means to ensure economic equity and sustainable development. It promotes innovation and development in the manufacturing sector, 
with the fundamental goal of improving competitiveness in all nations through dialogue and cooperation among the manufacturing sector's key players. The WMF supports national and international industrial agendas, provides a framework through which its stakeholders can meet and exchange opinions to find innovative solutions, disseminates knowledge through international and regional meetings and publications. This kind of events is also the best opportunity to share best practices experiences coming from research projects and to invite business and entrepreneurship experts/industry actors to give talks and interact with (potential) customers and partners. Always to support the observation phase, POLIMI defines educational programs allowing to attract and form next generation talent (forming I4.0 employees and workers). The main examples are the Master's Program in Industrial Engineering and the MBA and Masters' programs about Industry 4.0 topics.

Awareness: For those TUs interested in further collaborating with POLIMI, a maturity model, called DREAMY (Digital REadiness Assessment MaturitY model) is provided. Indeed, in the awareness phase manufacturers need to realise which is their digital status quo. DREAMY model assesses a manufacturing company's readiness level to trigger its digital transitioning process and to identify manufacturing company's strengths, weaknesses and opportunities, creating a roadmap for investments in digitisation and transitioning to smart manufacturing. Moreover, manufacturers need to understand and to evaluate how these new digital technologies are used to support their product development process along the entire company. Indeed, to deliver successful solutions in the market, companies can choose among various best practices to apply in their development process. Chaos-low-intermediatemature-best practice (CLIMB) model (Rossi and Terzi, 2017) measures maturity in product development activities. Together with DREAMY, CLIMB provides an evaluation also of the digital skills needed in the organization to better address the digital transformation of a TU. In addition, these services are the starting point for more structured collaborations aimed at increasing TU's digital maturity level through tailored paid projects. In the awareness phase, also Business-related services are provided. Technical assistance in the proposal development process to comply with specific proposal requirements (e.g., for project funding) can be the key to involve TUs in new European projects collaborations. In this phase, also open calls, launched throughout research projects, can be exploited to support the ideation of new technologies (several calls have been launched by POLIMI in the last years thanks to its belonging to different consortia). Finally, ecosystem services (as provision of trend reports, communication of technology related information to organization, and identification of emerging technologies) are provided. They can be provided also during Open Days including demonstrative applications of the Industry 4.0 Lab functionalities. Afterward, the generic TU can have access to specific didactic services, namely Corporate Education \& Training courses encompassing realistic demonstrations of I4.0 applications representing the state-of-the-art of manufacturing.

Experiment: In addition to the didactic services offered, companies would be provided with specific services aimed at experimenting applications in their specific fields. In particular, POLIMI makes available the facilities and instruments present in the Industry 4.0 Lab to support manufacturing TU in this sense. Doing this, POLIMI supports the development of proofs of concepts. In addition, strictly related to the 
technologies experimented, are provided data analysis services, followed by decision support services and user experience/navigation (dashboard and KPIs setting) service. Finally, contacts of POLIMI's ecosystem (secondment) can be provided in this phase.

Experience: To prepare the TU to best cope with the adoption phase's issues, POLIMI provides training on business skills and entrepreneurship (e.g., formal courses, workshops, seminars). In addition, secondment services are provided.

Adoption: Finally, once the TU has been specifically trained and has both experimented and experienced the technologies needed, POLIMI can provide secondment services to support TU in the very last phase of adoption.

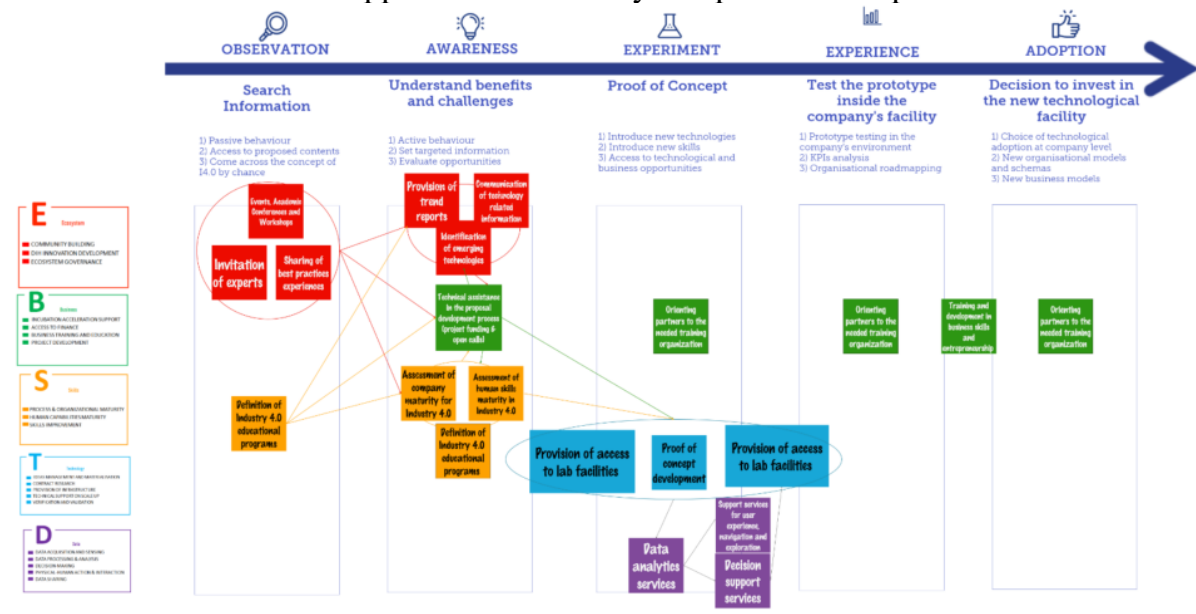

Figure 1. Technology Users Customer Journey: the POLIMI typical path

\subsubsection{Technology providers Customer Journey}

Ideation: The TP CJ starts with the Ideation step. During this first phase, POLIMI organizes (and also participates to) many public events like conferences, webinars, open days and workshops (e.g. of the Observatory Transition I4.0) that TPs can access to improve and update their knowledge on digital technologies and to get in contact with TUs. Indeed, such events can be focused on specific topics, to provide the extant state of theory and practice to both academics (professors, researchers, students, etc.) and practitioners (manufacturing companies and professionals). As stated in the TU's journey, one of the main events is the WMF. POLIMI also supports the IPR definition throughout the entire TP journey. Also Business-related services are provided: technical assistance in the proposal development process to comply with specific proposal requirements (e.g. for project funding) can be the key to involve TUs in new project collaborations. From this phase up to the last ones, open calls, launched throughout research projects, can be also exploited to support the ideation of new technologies (several calls have been launched by POLIMI in the last years).

Design and Engineering: In this phase, as in the case of TUs, ecosystem services (as provision of trend reports, communication of technology related information to organization, and identification of emerging technologies) are provided, also during dedicated events and Open Days, including demonstrative applications of the Industry 
4.0 Lab functionalities. Afterward, the TP can have access to specific didactic services, namely Corporate Education \& Training courses that encompass also realistic demonstrations of I4.0 applications (representing the State-of-the-Art of manufacturing). These courses can support TPs in either defining the PoC of the technology to be provided or improving and refining the design and engineering of their solutions. This combined Technology/Training service can be provided by POLIMI from this phase up to the Verification \& Validation. In addition, POLIMI provides services for user experience, navigation and exploration (through the configuration of dashboards and sets of KPI related to the developed technology).



Figure 2. Technology Providers Customer Journey: the POLIMI typical path

MVP: The development of an MVP is supported through the provision of secondment services to meet TP's needs. Otherwise, the access to the Industry 4.0 lab is provided to support them. Finally, educational programs in the I4.0 domain and the involvement in consortia and open calls can be catered in this phase.

Verification \& Validation: The same happens for the Verification \& Validation step. In case the Technology/Training services are not suitable to the TP' case, POLIMI provides secondment services. Also, the participation to new project consortia or open calls can be fostered. Finally, before the launch to the market, the generic TP may rely on POLIMI for training on business skills and entrepreneurship.

Go to Market: Also in this last step, POLIMI can provide secondment services.

\section{Discussions, Conclusions, and Future Work}

This paper has the aim of introducing the methodology used to build DIHs CJs. It supports the definition of flexible service workflows for DIH customers (i.e. TPs and TUs), by combining the services composing the DIH portfolio, configured through the D-BEST model, towards the implementation of DIHs Unique Value Proposition. 
Indeed, the method not only assesses the role of DIHs in catalysing the digitalization dynamics of SMEs but could also support the definition of the service pipeline of DIHs. Process gates have been defined along the two digital transformation paths of TU and TP, leading to the definition of the two 5-step paths towards the full digital maturity and awareness of the customer. Moreover, allocating and connecting typical D-BEST services along the two templates, the model demonstrated to be able to develop the two different CJs for the POLIMI DIH pilot case. Typical paths have been created for both TU and TP, revealing a different DIH value propositions per each of the two types of stakeholders. Among the main limitations of the method introduced there is the lack of the blocking points unlocked along the CJs through the support of DIHs. Indeed, although technology offers high potentials and DIHs foster the new technologies exploitation for SMEs, the percentage of companies giving up the CJ before its completion is relevant. For this reason, the CJs need to be enriched with the blocking points that SMEs might have to cope with when going through it. A limitation of this paper is the application of the CJ model only to the pilot case, the POLIMI DIH. From the future extensive use of the method, it is easy to hypothesise that some DIH will be more targeting the development and commercialisation of new CPS technologies, some others are more interested in creating awareness and investments in the demand side of the marketplace. Finally, based on the journeys presented in this paper, where the typical paths between TPs and TUs with the DIH have been indicated, success stories and best cases can be detected and be shared.

Acknowledgments. This work has received funding from the European Union's Horizon 2020 research and innovation programme under grant agreement No 872548 .

\section{References}

Butter, M. et al. (2019) 'Digital innovation hubs and their position in the European, national and regional innovation ecosystems', in Redesigning Organizations: Concepts for the Connected Society. Springer International Publishing, pp. 45-60. doi: 10.1007/978-3-03027957-8_3.

DIH4CPS - Digital Innovation Hub for Cyber-Physical Systems (2020). Available at: http://dih4cps.eu/ (Accessed: 9 May 2020).

DIH4CPS project (2020) D2 .1: DIH Service Catalogue for Ecosystem, Technology, Business Development - WP2: Network Setup and Management.

European Commission (2018) Smart Anything Everywhere - Digital Innovation Hubs Accelerators for the broad digital transformation of the European industry. Available at: https://ec.europa.eu/digital-single-market/en/news/communication-digitising-europeanindustry-reaping-full-benefits-digital-single-market (Accessed: 4 February 2020).

MIDIH Project (2020) D3.4 Specifications and Design of DIH/CC Services 2 - WP3 Network of Competence Centers and Pan-EU DIHs in CPS/IoT.

Sassanelli, C. et al. (2020) 'Towards a reference model for configuring services portfolio of Digital innovation hubs: the ETBSD model', in Camarinha-Matos, L. M. (ed.) IFIP International Federation for Information Processing 2020, PRO-VE 2020, IFIP AICT 598. Valencia (Virtual), Spain: Springer Nature Switzerland AG 2020, pp. 597-607. doi: https://doi.org/10.1007/978-3-030-62412-5_49.

Ulrich, K. T. and Eppinger, S. D. (2012) Product Design and Development, Product Design and Development. doi: 10.1016/B978-0-7506-8985-4.00002-4. 